\title{
A influência da deficiência estrogênica no processo de remodelação e reparação óssea
}

\section{Effect of estrogen deficiency on bone turnover and bone repair}

Susana Ungaro Amadei'; Vanessa Ávila Sarmento Silveira'; Andresa Costa Pereira'; Yasmin Rodarte Carvalho'; Rosilene Fernandes da Rocha ${ }^{3}$

\section{unitermos Osso e ossos \\ Remodelação óssea \\ Osteoporose pós-menopausa \\ Fratura}

Deficiência estrogênica

\section{resumo}

Introdução: Nestes últimos anos, descobriu-se a complexidade dos mecanismos que influenciam a atividade óssea, e grande parte das pesquisas direcionou-se para o estudo de fatores capazes de modular as funções ósseas. Essa expansão da pesquisa deve-se, em parte, ao reconhecimento da osteoporose como importante problema na velhice. A osteoporose constitui uma das osteopatias mais comuns, caracterizando-se pela redução da massa óssea, determinada, por sua vez, pelo desequilíbrio entre reabsorção e neoformação. Objetivo: Apresentar uma revisão da literatura sobre os principais aspectos da remodelação e da reparação associados à deficiência estrogênica. Remodelação óssea: $\mathrm{O}$ osso apresenta processo contínuo de remodelação, entretanto anormalidades nesse processo ocorrem em algumas doenças, entre elas a osteoporose, sendo que a deficiência estrogênica parece ter o papel principal na sua gênese. Reparação óssea: Tal processo envolve uma cascata complexa de respostas biológicase, assim como a remodelação, é afetado por fatores locais e externos e regulado pela interação de diferentes mecanismos. Portanto, o aumento ou o decréscimo da capacidade de reparação óssea têm sido relacionados a alterações ocorridas na remodelação. Deficiência estrogênica e metabolismo ósseo: A maioria dos autores sugere uma redução na capacidade de remodelação e de reparação do tecido. Discussão: Ainda não está determinado qual estágio da reparação é mais alterado, se a fase inicial de formação do calo ósseo, se a de mineralização ou se a fase tardia da reparação, a remodelação óssea. Conclusão: Como os mecanismos fisiológicos e a patogênese das alterações ósseas causadas pela deficiência estrogênica não estão completamente estabelecidos, novas pesquisas ainda são necessárias.

Introduction: In the past few years, it was recognized the great complexity of the mechanisms that influence bone cellular activity and several studies focus on the factors able to modulate the bone functions. The increase of bone research is, in part, due to the establishment of osteoporosis as a healthy problem common in elderly. Osteoporosis is one of the most important osteopathy, characterized by the bone mass reduction, resulted from disequilibrium between bone resorption and bone formation. Objective: Based on the relationship between estrogen and bone metabolism, the aim of this study is present a review of literature about the principal aspects of bone turnover and bone repair associated to estrogen deficiency. Bone turnover: Bone tissue is in continuous turnover, however, changes in this process can result in some disorders, such as osteoporosis. Bone repair: Involves a sequence of biological events. It is affected by local and external factors and regulated by interaction of several mechanisms, like bone turnover. Estrogen deficiency and bone metabolism: The capacity to repair has been associated to changes in bone turnover and repair. Discussion: It is not known which bone repair stage is modified: the bone formation, the mineralization or the resorption stage. Conclusion: The pathophysiology of bone changes caused by estrogen deficiency are not completely clear, so, new studies are still necessary.

1. Doutorandas em Biopatologia Bucal do Departamento de Biociências e Diagnóstico Bucal da Faculdade de Odontologia de São José dos Campos da Universidade Estadual Paulista (UNESP).

2. Professora-adjunta da disciplina Patologia Bucal do Departamento de Biociências e Diagnóstico Bucal da Faculdade de Odontologia de São José dos Campos da UNESP.

3. Professora-doutora das disciplinas de Patologia Geral e Farmacologia do Departamento de Biociências e Diagnóstico Bucal da Faculdade de Odontologia de São José dos Campos da UNESP 


\section{Introdução}

Com o aumento da expectativa de vida da população brasileira propiciado por muitos fatores, entre eles os avanços obtidos com as pesquisas e descobertas de novos tratamentos, vem crescendo o número de pessoas acima dos 65 anos de idade, o que, conseqüentemente, vem acompanhado de várias alterações da senescência. Entre essas alterações nos deparamos com doenças crônicas, como diabetes, hipertensão, problemas vasculares, artrite, osteoporose e outras. Essas patologias estão sendo mais bem estudadas com a finalidade de proporcionar melhor qualidade de vida.

O conhecimento sobre os múltiplos mecanismos ósseos regulatórios deve tanto auxiliar o entendimento sobre a remodelação óssea quanto oferecer explicações para as alterações que ocorrem em várias enfermidades, sendo esse estudo de extrema importância ${ }^{(23)}$. Nos últimos anos tem-se descoberto a grande complexidade dos mecanismos que influenciam a atividade celular óssea, e a vasta expansão de pesquisas sobre esse assunto vem ganhando êxito, em parte devido ao reconhecimento da osteoporose como importante doença que acomete os idosos ${ }^{(2)}$.

A osteoporose está relacionada ao metabolismo ósseo, alterando a microarquitetura dos ossos, inclusive os da face. Várias áreas da medicina e da odontologia têm grande interesse no tecido ósseo e no seu conteúdo mineral, sob diferentes pontos de vista, levando ao estudo de medicamentos que possam auxiliar o processo de remodelação e reparação ósseas.

Assustadoras são as projeções feitas com relação à osteoporose para os próximos anos. Estima-se que 200 milhões de pessoas em todo o mundo sejam atingidas pela osteoporose, a mais importante doença músculo-esquelética, não-artrítica, que afeta não somente os idosos, mas também as mulheres de meia-idade. Tal situação tende a se agravar nos próximos anos, não só pelo aumento do número de idosos, como também pela maior expectativa de vida em praticamente todo o mundo(44).

No Brasil, a cada ano, 70 mil pessoas fraturam o colo do fêmur, sendo que pelo menos $20 \%$ morrem de complicações nos primeiros seis meses e metade nunca mais tem uma vida independente. Além disso, 20\% a 30\% necessitarão de cuidados institucionais ou de enfermagem domiciliar ${ }^{(44)}$.

Na osteoporose, os ossos tornam-se menos resistentes, mas a concentração de cálcio na matriz orgânica é normal. Todavia, a quantidade de tecido ósseo é menor, apresentando o osso amplos canais de reabsorção. Essa condição patológica decorre da diminuição na formação óssea, do aumento na reabsorção do osso formado, ou da combinação dos dois fatores ${ }^{(29)}$. O reconhecimento das alterações na quantidade de células ósseas, bem como das atividades, é o maior avanço no entendimento dos mecanismos dessa doença ${ }^{(38)}$, os quais vêm sendo investigados nas últimas décadas com base no interesse neste processo biológico ${ }^{(4)}$.

A fisiopatologia da osteoporose é complexa, envolvendo liberação de fatores de crescimento e citocinas ${ }^{(20)}$. Manolagas ${ }^{(37)}$ sugeriu ser a interleucina 6 (IL-6) a citocina de maior importância na perda óssea quando ocorrem disfunções gonadais, entretanto o seu papel parece ainda incerto, embora a IL-1, o fator de necrose tumoral (TNF) e a IL-11 também possam participar dessa perda causada pela deficiência estrogênica. Porém, em contraste com a IL-6, essas citocinas não são suprimidas pelos hormônios esteroidais, não podendo ser consideradas causadoras dessa condição patológica. Com base nessas afirmações, um dos maiores desafios para os biologistas celulares é entender como estes múltiplos fatores de crescimento interagem no tecido ósseo ${ }^{(47)}$.

Com a diminuição da secreção de estrógenos na menopausa, tem-se como conseqüência maior atividade metabólica óssea, ou seja, maior ritmo na remodelação óssea ${ }^{(3)}$.

A osteoporose na menopausa é de extrema relevância para a área da saúde ${ }^{(59) 9}$, posto que constitui uma das doenças metabólicas ósseas mais comuns e significativas. A diminuição do estrógeno é o fator determinante e responsável pela gênese da osteoporose após a menopausa ${ }^{(3)}$, sendo a perda óssea mais intensa nos cinco anos que se seguem a ela ${ }^{(13,20)}$. Por isso, essa condição é mais freqüente e mais dramática nas mulheres, que chegam a perder cerca de $40 \%-50 \%$ da massa óssea até o final da vida ${ }^{(1)}$.

A osteoporose atinge uma em cada quatro mulheres na menopausa e, após os 65 anos, uma em cada três. A redução da massa óssea após a menopausa apresenta relação primária com o funcionamento ovariano ${ }^{(43)}$.

Devido à relação entre o estrógeno e o metabolismo ósseo, o objetivo deste trabalho foi apresentar uma revisão da literatura sobre os principais aspectos da remodelação óssea e do processo de reparação associados à deficiência estrogênica.

\section{Remodelação óssea}

Os avanços nos estudos em biologia óssea durante as duas últimas décadas contribuíram para o melhor entendimento sobre a regulação da remodelação óssea e permitiram definir algumas questões ainda não-respondidas ${ }^{(23)}$.

$\mathrm{O}$ osso é um tecido extremamente ativo ${ }^{(3,29)}$. No esqueleto em desenvolvimento, essa atividade é primariamente voltada para o crescimento e a modelação óssea, processos pelos quais o osso atinge sua forma e seu tamanho. No adulto, a atividade metabólica envolve predominantemente a remodelação ${ }^{(30,52)}$. 
A remodelação óssea é definida como um processo de aposição no qual há remoção localizada do osso antigo (reabsorção) e substituição por osso recentemente forma$\mathrm{do}^{(23,41)}$. Esse evento continua por toda a vida adulta do indivíduo, sendo responsável pela renovação do esqueleto e mantendo sua integridade anatômica e estrutural( $(8,16,38)$.

A remodelação óssea é um processo fisiológico constante no qual a formação óssea é correspondente à reabsorção, sendo regulada por diversos fatores, como mecanismos regulatórios intracelulares, influência hormonal, fatores locais e externos. Alterações nesse processo podem resultar em diferentes distúrbios, entre eles a osteoporose ${ }^{(48)}$.

O processo de remodelação ocorre em pequenos conjuntos de células chamadas de unidades multicelulares básicas de remodelação óssea (BMU), sendo caracterizado pelo acoplamento das funções dos osteoclastos e osteoblastos. Cada unidade é geográfica e cronologicamente separada de outros conjuntos ${ }^{(6,18)}$, sugerindo que a ativação de seqüência de ocorrências celulares responsáveis pela remodelação seja também controlada localmente por fatores gerados no microambiente ósseo ${ }^{(18)}$.

O sinal que inicia a remodelação não está completamente identificado, mas é evidente que forças mecânicas podem ser capazes de alterar a arquitetura óssea local ${ }^{(29,61)}$.

O primeiro estágio da remodelação envolve o recrutamento das células precursoras de osteoclasto para o osso. Essas, presentes em tecidos hematopoéticos, como na medula óssea, respondem a sinais físicos e hormonais, e, concentrando sobre determinada região da superfície óssea que será reabsorvida, fundem-se e transformam-se em osteoclastos multinucleados ${ }^{(7,33)}$.

Recentes evidências têm sugerido que o osteoclasto é uma célula secretora que produz fatores que podem estimular sua própria formação e atividade. Estudos demonstraram que células osteoclásticas, formadas em cultura de células medulares de pacientes com doença de Paget, produzem IL-6 capaz de estimular a formação de osteoclastos e reabsorção óssea ${ }^{(50)}$.

A diferenciação das células progenitoras em osteoclastos ocorre por meio de um mecanismo que envolve a interação célula a célula com células osteoblásticas ${ }^{(55)}$. Após a diferenciação, a superfície óssea é preparada com a remoção da camada de osteóide não-mineralizado pelos osteoblastos de revestimento que produzem enzimas proteolíticas, como as metaloproteinases, colagenases e gelatinases. Esse processo facilita o acesso dos osteoclastos ao osso subjacente ${ }^{(42)}$.

A osteoprotegerina (OPG), receptor ativador de fator de necrose tumoral (NF-kB [RANK]), e a citocina RANK ligante (RANKL) têm sido identificadas como os principais fatores envolvidos na gênese de osteoclastos. A RANK localiza-se na superfície de precursores de osteoclastos e de osteoclastos maduros, enquanto a RANKL é uma proteína pertencente à família do TNF. Seu principal papel é a inibição da apoptose dos osteoclastos e a estimulação da diferenciação e ativação dessas células. A OPG pode atuar inibindo a RANKL por meio da ligação com RANK e também diretamente, por meio de outros receptores presentes nos osteoclastos. Seus efeitos são antagônicos aos da RANKL. Diversas citocinas e compostos, como os estrógenos, influenciam a gênese de osteoclastos por meio da regulação da produção de RANKL/ OPG pelas células estromais e pelos osteoblastos ${ }^{(54)}$.

O próximo passo consiste no reconhecimento das proteínas da matriz óssea extracelular por meio de proteínas de membrana celular chamadas integrinas ${ }^{(16)}$. A seguir são formadas a borda vilosa e as zonas claras, essas livres de organelas e ricas em filamentos de actina. Através das zonas claras são formadas poderosas adesões focais, responsáveis pela forte interação célula/substrato e pelo isolamento do espaço externo abaixo da célula (lacuna de reabsorção), onde a borda vilosa se espalha na superfície óssea ${ }^{(30,55)}$.

A ativação osteoclástica é o terceiro evento, provavelmente iniciado pelos fatores liberados pelos osteoblastos e por meio também de contato célula a célula ${ }^{(19)}$.

Em seguida, em fase de reabsorção, os osteoclastos ativados degradam tanto os componentes minerais quanto os orgânicos, pela secreção de enzimas ácidas e hidrolíticas, liberando fragmentos minerais ósseos e de colágeno. Os osteoclastos são estimulados por calcitriol, paratormônio (PTH), TNF, prostaglandina $E_{2}$, além das IL-1, 11 e 6, e são inibidos por IL-4 e 13. O que encerra essa fase pode ser um elevado nível de cálcio local ou substâncias liberadas pela própria matriz ${ }^{(3)}$.

O osso é uma fonte rica em fatores de crescimento, importantes na regulação do processo de remodelação óssea ${ }^{(38)}$. Os osteoclastos, além de sua função osteolítica, desempenham importante papel no desenvolvimento e crescimento ósseos, ao liberar esses fatores da matriz extracelular mineralizada. Tais fatores estimulam os osteoblastos a se proliferarem e a sintetizar proteínas da matriz ${ }^{(40,41)}$. Em seguida, ao completarem o ciclo da reabsorção, secretam proteínas que servirão de substrato para a fixação do osteoblasto ${ }^{(40)}$.

Os osteoclastos sofrem apoptose, possivelmente induzida pelo fator de crescimento transformante beta (TGFbeta), responsável também pelo bloqueio da reabsorção óssea e pela atração dos osteoblastos ${ }^{(27)}$. Ao contrário do TGF-beta, o PTH e a $1,25(\mathrm{OH})_{2} \mathrm{D}_{3}$ inibem a apoptose in vitro do osteoclasto ${ }^{(50)}$.

Em próximo estágio, denominado fase de reversão, células mononucleares da linhagem monócitos e macrófagos preparam a superfície para novos osteoblastos iniciarem a formação óssea, produzindo uma glicoproteína à qual os osteoblastos podem se aderir ${ }^{(3)}$.

Caracterizando a fase seguinte, a formação óssea resulta de complexa cascata de eventos que envolvem a proliferação 
de células mesenquimais primitivas, diferenciação em células precursoras osteoblásticas (pré-osteoblasto), maturação dos osteoblastos, formação de matriz e mineralização ${ }^{(23,33)}$.

Os osteoblastos são células que sintetizam a parte orgânica da matriz óssea. São capazes de concentrar fosfato de cálcio, participando da mineralização do osso. Os produtos de secreção dessas células são: fosfatase alcalina, ácido hialurônico, sulfato de condroitina, osteopontina, osteonectina, sialoproteína óssea, pró-colagenase, ativador de plasminogênio e proteína morfogenética do osso (BMP), entre outras ${ }^{(32)}$.

Essas células possuem receptores para diversos fatores, como PTH, glicocorticóides, hormônio do crescimento $(\mathrm{GH})$, além de IL-1, TNF-alfa, prostaglandinas e fator de crescimento semelhante à insulina (IGF), além de receptores para hormônios sexuais ${ }^{(3,32)}$. Dispõem-se nas superfícies ósseas, lado a lado, em arranjo que lembra um epitélio simples. Quando em intensa atividade sintética, são cubóides e, em estado pouco ativo, tornam-se achatados ${ }^{(29,30,32)}$. Os osteoblastos convergem para o fundo da cavidade de reabsorção e formam espessa camada de osteóide. As células gradualmente se achatam, tornando-se quiescentes ${ }^{(23)}$. Uma vez aprisionado pela matriz recém-sintetizada, o osteoblasto passa a ser chamado de osteócito ${ }^{(29,30,32) .}$

Os osteoblastos se proliferam mediados por fatores de crescimento liberados pelos próprios osteoblastos e pelo osso durante o processo de reabsorção ${ }^{(46)}$. Entre os mais importantes estão o TCF-beta ${ }^{(14,32)}$ e os fatores liberados pela matriz óssea, como o IGF-I e II, o fator de crescimento fibroblástico (FGF) e o fator de crescimento derivado de plaquetas $\left(\right.$ PDGF) ${ }^{(46)}$. Pode ser que esses fatores auxiliem na formação óssea, também impedindo a apoptose osteoblástica ${ }^{(23)}$.

Ao sintetizarem novo colágeno e outras proteínas de matriz, preenchendo a cavidade de reabsorção com osteóide lamelar novo, a deposição mineral inicia-se subseqüentemente e prolonga-se durante vários dias, tempo suficiente para que o colágeno forme suas pontes de ligação. Apenas poucos osteoblastos permanecem presos à matriz em mineralização, transformando-se em osteócitos, enquanto a maioria sofre apoptose ${ }^{(3)}$. O fim da atividade osteoblástica pode ser devido à inibição por feedback negativo ou à indução da apoptose do osteoblasto pelo TNF liberado pelas células medulares vizinhas(23).

Entre os fatores de crescimento encontrados no osso, alguns são produzidos pelas células ósseas, como IGF, TGF, FGF, PDGF e BMP. Outros, como IL-1 e TNF-alfa, são produzidos por tecidos relacionados ${ }^{(52)}$.

Os fatores de crescimento, portanto, exercem função sobre as células ósseas de forma autócrina ou parácrina, e não endógena. São produzidos por células ósseas, células adjacentes vasculares e hematopoéticas. A ligação desses fatores, como as citocinas, aos receptores de membrana celular gera um sinal ao núcleo, que resulta na transcrição de genes específicos. As IL-1 e 7, assim como o TNF-alfa, estimulam a reabsorção e inibem a formação óssea, enquanto as IL-6 e 11 também estimulam a reabsorção, mas também a formação, e as IL-4, 13 e 18 inibem apenas a reabsorção óssea. Prostaglandinas, leucotrienos e óxido nítrico (ON) são fundamentais na resposta rápida do osso a ações mecânicas e inflamatórias. As primeiras têm efeitos bifásicos na reabsorção e formação, mas o efeito predominante é estimulador. O ON inibe os osteoclastos, enquanto os leucotrienos estimulam a reabsorção óssea ${ }^{(3)}$.

Sistemicamente, a função das células ósseas é alterada principalmente pelos hormônios reguladores do metabolismo de cálcio: PTH, vitamina D e calcitonina ${ }^{(10)}$.

Outros hormônios também interferem no metabolismo ósseo, entre eles $\mathrm{GH}$, glicocorticóides, hormônios tireoidianos e sexuais ${ }^{(10)}$.

\section{Reparação óssea}

Além das excelentes propriedades mecânicas, o osso revela um potencial único para reparação. $\mathrm{O}$ tecido ósseo é capaz de reparar fraturas ou defeitos locais por meio do processo de regeneração, com a formação de novo tecido com a mesma organização estrutural do tecido anterior, sem a formação de cicatriz ${ }^{(52)}$.

Após uma lesão óssea, uma seqüência de eventos dinâmicos ocorre com o objetivo de restaurar a forma e a função do osso. Muitos desses mecanismos biológicos celulares ainda não foram completamente identificados, porém sabe-se que o processo é ativado pela liberação de fatores de crescimento e citocinas no local(24).

A reparação óssea é semelhante tanto para pequenas quanto para grandes injúrias, para fraturas ósseas e para defeitos cirúrgicos. Quando um osso é lesado, periósteo, vasos na cortical, medula e tecidos circundantes são rompidos. Ocorre um sangramento oriundo das margens do tecido ósseo lesado e dos tecidos moles vizinhos. É formado um hematoma ou coágulo sangüíneo dentro do canal medular, entre as extremidades da fratura óssea e o periósteo ${ }^{(45,60)}$.

O coágulo que ocorre após a fratura consiste em extravasamento de eritrócitos, fibrina e plaquetas, que liberam PDGF, FGF e TGF-alfa, fatores quimiotáticos e reguladores da atividade celular ${ }^{(24)}$.

Para que o reparo se inicie, o coágulo sangüíneo e os restos celulares e da matriz devem ser removidos pelos macrófagos ${ }^{(29)}$. Simultaneamente à formação do coágulo, o tecido imediatamente adjacente à fratura se necrosa. Esse tecido necrótico estimula intensa resposta inflamatória, caracterizada por vasodilatação, exsudação do plasma, leucócitos e células mesenquimais ${ }^{(45,60)}$. 
Aproximadamente do terceiro ao quinto dia após a fratura, o periósteo e o endósteo respondem com intensa proliferação, formando um tecido conjuntivo muito rico em células osteogênicas, o qual constitui um colar em torno da fratura e penetra entre as extremidades ósseas rompidas, sendo denominado calo fibroso. Células endoteliais derivadas dos tecidos circunjacentes migram, proliferam-se e formam novos capilares que penetram no hematoma. $\mathrm{O}$ estímulo para essa nova formação vascular parece ser a hipóxia local. A angiogênese ocorre em direção a um gradiente químico, que pode ser estabelecido pela hipóxia e pela concentração de quimiotáticos, como PDGF e $\operatorname{FGF}^{(24,29)}$.

Osteoblastos de dentro do calo sintetizam colágeno e matriz, portanto, nesse anel ou colar conjuntivo, bem como no conjuntivo que se localiza entre as extremidades ósseas fraturadas, surge tecido ósseo imaturo, tanto pela ossificação endocondral de pequenos pedaços de cartilagem que se formam, como também por ossificação intramembranosa. Esse processo evolui de modo a aparecer, após algum tempo, o calo ósseo, o qual é constituído de tecido ósseo imaturo, que se formou de modo desordenado, caracterizado por arranjo irregular dos osteócitos e orientação irregular das fibras colágenas ${ }^{(29,60)}$.

Enquanto o processo de reparo continua, ocorre remodelação óssea, o calo se torna desnecessário, sendo reabsorvido, e as trabéculas são formadas e orientadas ao longo de linhas de esforços e se tornam funcionais. A velocidade desse processo depende de alguns fatores locais e sistêmicos, entre eles tipo de tecido ósseo a ser reparado (cortical ou esponjoso), presença de infecção, hemorragias, imobilização local, idade e alterações nutricionais ${ }^{(45,60)}$.

Em locais com excessiva mobilidade, pode ocorrer o desenvolvimento de cartilagem, tecido que possui menos exigências metabólicas do que o osso. Quando o tecido é imobilizado, o reparo ocorre por meio de formação óssea primária(24).

Durante esse processo dinâmico, as células ósseas não atuam isoladamente. Elas são reguladas por interações sistêmicas, realizadas pelo sistema endócrino, por meio da liberação de diversos hormônios: PTH, calcitonina, insulina, $\mathrm{GH}$, hormônios esteróides e da tireóide ${ }^{(24)}$.

Localmente, certos fatores de crescimento foram identificados, como PDGF, IL-1, FGF, TGF-alfa e beta, fator de crescimento epidérmico (EGF), entre outros. Os PDGF induzem tanto fibroblastos quanto fibras musculares a se proliferarem. Também são quimiotáticos para leucócitos e fibroblastos. A IL-1 estimula os fibroblastos a se proliferarem e a produzirem colágeno e controla o crescimento das células endoteliais ${ }^{60}$. Os FGF são da família dos que estimulam o endotélio vascular, os fibroblastos e as fibras musculares lisas e induzem a formação de novos vasos. $\mathrm{O}$ TGF-alfa influencia o TGF-beta quanto ao índice de proliferação de muitas células. O EGF é mitogênico para células mesenquimais (osteoblastos) e epiteliais ${ }^{(57,60)}$.
Certos componentes da matriz extracelular regulam a proliferação e a quimiotaxia. São chamados moléculas de adesão do substrato. Uma dessas moléculas, a fibronectina, produzida por fibroblastos, macrófagos e células endoteliais, exerce diversos efeitos no processo da reparação. A fibronectina é adesiva e parece facilitar a migração de células inflamatórias para dentro da ferida, juntamente com o gel de fibrina/fibronectina. Além disso, estimula a liberação de FGF pelos macrófagos, sendo quimiotática para essas células e também para fibroblastos. Outras moléculas de adesão incluem tenascina, laminina, heparan-sulfato e colágeno tipos IV, $\mathrm{V}$ e V ${ }^{(60)}$.

\section{Deficiência estrogênica e metabolismo ósseo}

Os estrógenos são hormônios que produzem numerosas ações fisiológicas, incluindo efeitos no desenvolvimento, ações neuroendócrinas envolvidas no controle da ovulação, preparo cíclico do trato reprodutor para fertilização e implantação do óvulo e ações no metabolismo de minerais, carboidratos, proteínas e lípides. O uso terapêutico dos estrógenos é disseminado, sendo comumente utilizados na reposição hormonal após a menopausa e na anticoncepção( ${ }^{(64)}$.

Os ovários são a principal fonte de estrógeno circulante. O principal produto secretório é o estradiol, sintetizado pelas células granulosas a partir de precursores androgênicos (androstenediona ou testosterona), proporcionados pelas células da teca ${ }^{(64)}$.

Os hormônios sexuais têm importante papel no crescimento ósseo e na manutenção do pico de massa óssea ${ }^{(12)}$. Existem claras evidências de que a diminuição ou ausência de estrógenos leva a progressiva redução da massa óssea. Assim, na ooforectomia em jovens, ou na menopausa precoce, pode-se observar acelerada perda óssea com instalação mais rápida da osteoporose $e^{(6)}$.

Os estrógenos possuem variadas atuações, entre elas o crescimento, a diferenciação e a função de muitos tecidos. Os mecanismos pelos quais esse hormônio age não estão completamente claros, mas sabe-se que seu mecanismo de ação envolve interação entre uma molécula ligante e um receptor ${ }^{(12)}$.

A presença de receptores estrogênicos em osteoblastos ou em células de linhagem osteoblástica foi descrita por Eriksen et al.(17), que detectaram receptores funcionais de estrógeno em células ósseas humanas, e por Komm et al. ${ }^{(34)}$, que encontraram diversos locais de ligação do estrógeno em núcleos de células de ratas. Ambos os trabalhos relataram a presença de RNA mensageiro (RNAm) estrogênico em cada população de células óssea estudadas.

Embora os receptores de estrógeno estejam predominantemente em osteoblastos, a principal atuação desse 
hormônio é na reabsorção óssea ${ }^{(58)}$. Hughes et al.(27) investigaram a capacidade de o estrógeno afetar a função osteoclástica pela indução da apoptose. O 17-beta-estradiol promoveu apoptose em osteoclastos de ratos in vitro e in vivo. Esses achados sugerem que os estrógenos podem prevenir perda óssea excessiva antes e após a menopausa pela indução da apoptose dos osteoclastos.

A ligação de citocinas nos receptores osteoblásticos provoca a liberação de fatores solúveis que agem sobre a linhagem osteoclástica estimulando sua atividade. É possível que a ligação do estrógeno ou de seus análogos aos receptores dos osteoblastos iniba a liberação de fatores estimuladores dos osteoclastos ou aumente a atividade dos fatores inibidores dos mesmos ${ }^{(56)}$.

$O$ receptor de estrógeno encontra-se em tecidos do trato reprodutivo em concentração que varia de 10 mil a 100 mil moléculas por célula, porém, em outros tecidos, como o ósseo, está presente em níveis bem mais baixos, cerca de 200 a 1.200 moléculas por célula. A especificidade do hormônio é determinada pelo domínio de ligação do estrógeno na região do receptor, e a resposta do tecido depende do número de receptores ${ }^{(62)}$.

O receptor se liga de maneira reversível ao estrógeno com altas afinidade e especificidade. A ativação do receptor parece envolver uma mudança conformacional capaz de ligá-lo ao receptor nuclear ${ }^{(51)}$. A resposta biológica à ação do estrógeno é um fenômeno saturável. O número de receptores por massa de tecido é limitado(21).

Entre as citocinas com propriedades de reabsorção, moduladas pelo estrógeno, destaca-se a IL-1. A deficiência estrogênica provoca aumento na secreção dessa citocina, potente indutora da reabsorção óssea ${ }^{(25)}$. Outro possível mecanismo da ação estrogênica faz-se pela intervenção da IL-4, que inibe a diferenciação dos osteoclastos. Porém o fator mais influenciado pelo estrógeno é o TGF-beta, produzido por muitas células, inclusive os osteoblastos. Para os osteoblastos constitui importante agente mitogênico, mas, quanto aos osteoclastos, diminui seu recrutamento e sua atividade reabsortiva. Os IGF, inicialmente produzidos pelos osteoblastos e incorporados dentro da matriz, assim como o TGF-beta, são liberados com a atividade osteoclástica. Ao serem liberados, estimulam a proliferação e a diferenciação osteoblástica, porém também possuem ação parácrina sobre os osteoclastos. Os estrógenos inibem a reabsorção óssea prevenindo a liberação desses fatores de crescimento previamente depositados na matriz óssea(62).

Os estrógenos e seus análogos apresentam importante papel na expressão de fatores de crescimento e de citocinas sintetizadas e secretadas pelos osteoblastos ou pelos osteoclastos. Esses mediadores celulares são responsáveis pelo equilíbrio funcional das células ósseas, determinando um controle autócrino e parácrino da remodelação óssea ${ }^{(62)}$.

Steeve et al. ${ }^{(54)}$ afirmaram que tanto os estrógenos quanto o TGF-beta aumentam a produção de OPG, diminuindo, conseqüentemente, a diferenciação e a ativação dos osteoclastos, bem como induzindo a apoptose dessas células.

A influência da deficiência estrogênica na reparação óssea alveolar foi investigada por Kawamoto e Nagaoka (31), que observaram que as alterações ósseas alveolares induzidas por oclusão traumática são agravadas pelos baixos níveis de estrógeno de ratas ovariectomizadas. Eles verificaram que a dinâmica óssea alveolar induzida pelo trauma oclusal foi aumentada pela deficiência estrogênica conseqüente à remoção dos ovários.

Shimizu et al. ${ }^{(53)}$ estudaram, por microscopia eletrônica de varredura, o processo de reparo ósseo após exodontia em ratas ovariectomizadas. Observaram que a ovariectomia estimulou a reabsorção óssea e que esta e a formação óssea ocorreram em locais específicos da superfície óssea alveolar.

Hsieh et al. (26) analisaram o efeito da ovariectomia no reparo de alvéolos dentários em ratas e verificaram que a deficiência estrogênica pode afetar a remodelação óssea pós-exodontia.

O processo da reparação óssea envolve uma cascata complexa de respostas biológicas e, assim como a remodelação óssea, é afetado também por fatores locais e externos e regulado pela interação de diferentes mecanismos (24). Portanto, o aumento ou o decréscimo da capacidade de reparação óssea têm sido relacionados a alterações ocorridas no processo da remodelação(63).

A experiência clínica em relação à alteração na reparação óssea causada pela osteoporose é inconsistente ${ }^{(36)}$. Poucos estudos foram realizados sobre as diferenças de reparação óssea entre indivíduos normais e com osteoporose e sugerem redução na capacidade de remodelação e de reparação desse tecido $(9,11,28,39,49)$.

Lill et al. ${ }^{(36)}$ demonstraram um atraso na reparação de fraturas em tíbias de ovelhas com osteoporose em relação à formação, mineralização e às propriedades mecânicas do calo ósseo. Entretanto, ainda há discordância entre os autores sobre a fase da reparação óssea mais prejudicada pela ovariectomia. Walsh et al. ${ }^{(63)}$ analisaram as propriedades mecânicas do reparo de fraturas em fêmures de ratas ovariectomizadas e normais e verificaram que, nos menores períodos de sacrifício (duas e quatro semanas), a ovariectomia alterou a reparação da fratura.

Segundo Blythe e Burchsbaum ${ }^{(5)}$, o estrógeno não altera a fase de mineralização. Os autores avaliaram o efeito do estrógeno na reparação de fraturas em fíbulas. A análise da resistência à tensão no local do reparo não revelou diferença significante entre os grupos tratado e controle. Entretanto, $\mathrm{Xu}$ et al. ${ }^{(65)}$ verificaram que a osteoporose influencia a quantidade e a qualidade do calo ósseo durante os estágios precoces do reparo de fratura óssea, podendo ter relação com o decréscimo da expressão de TGF-beta-1 em osteoblastos.

Kubo et al. ${ }^{(35)}$ não encontraram diferenças na reparação óssea entre o grupo ovariectomizado e o grupo controle até as primeiras seis semanas, contudo, 12 semanas após a fratura, foram observadas alterações histológicas osteoporóticas 
e diminuição da densidade mineral óssea (DMO), sugerindo que a ovariectomia afeta a reparação óssea em seus períodos tardios e não interfere no processo em suas fases iniciais.

Trabalhos existentes na literatura relatam que a ligação desse hormônio ou de seus análogos aos receptores dos osteoblastos inibe a liberação de fatores estimuladores dos osteoclastos ou aumenta a atividade dos fatores inibidores dos mesmos ${ }^{(56)}$. De acordo com Turner et al. ${ }^{(62)}$, o fator mais influenciado pelo estrógeno é o TGF-beta, que também é produzido pelos osteoblastos e atua sobre os osteoclastos diminuindo seu recrutamento e sua atividade reabsortiva. Hughes et al. ${ }^{(27)}$ verificaram que o 17-beta-estradiol promoveu apoptose em osteoclastos de ratos in vitro e in vivo.

\section{Conclusão}

Os avanços nos estudos do tecido ósseo têm contribuído para uma maior compreensão tanto da remodelação óssea quanto do seu processo de reparação. O reconhecimento da osteoporose pós-menopausa como importante problema de saúde pública deu origem a diversos estudos sobre a relação da deficiência estrogênica com o metabolismo ósseo. De acordo com a literatura, a diminuição dos níveis de estrógeno altera tanto o processo de remodelação quanto o de reparação, embora nem todos os mecanismos estejam completamente elucidados. Em relação à reparação óssea, ainda não está determinado qual estágio é mais alterado pela deficiência estrogênica, se a fase inicial de formação do calo ósseo, se a fase de mineralização ou, ainda, se a fase mais tardia da reparação, a remodelação óssea. Portanto, visto que os mecanismos fisiopatológicos citados e a patogênese ainda não estão completamente estabelecidos, novas pesquisas relacionadas ao entendimento destas alterações ainda são necessárias.

\section{Referências}

I. AIRES, M. M. et al. Fisiologia. Rio de Janeiro: Guanabara Koogan, |99|. 795p.

2. ARNETT,T. R. Update on bone cell biology. European Journal of Orthodontics, v. 12, p. 81-90, 1990.

3. BANDEIRA, F. et al. Osteoporose. I ed. Rio de Janeiro: Medsi, 2000. 390p.

4. BLAIR, H. C. How the osteoclast degrades bone? BioEssays, v. 20 n. 10, p. 837-46, 1998.

5.BLYTHE,J. G.; BUCHSBAUM,H.J. Fracture healing in estrogen-trated and castrated rats. Obstet Gynecol, v. 48, n. 3, p. 35I-2, 1976.

6. BORELLI,A. Envelhecimento ósseo: osteoporose. In: CARVALHO FILHO, E. T.; PAPALÉO NETTO, M. Geriatria: fundamentos, clínica e terapêutica. São Paulo: Atheneu, 1994. cap.22, p. 297-308.

7. BOYDE,A.;ALI, N. N.; JONES, S. J. Resorption of dentine by isolated osteoclasts in vitro. Br Dent J, v. I56, n. 6, p. 21 6-20, 1984.

8. BROWN, J. P.; JOSSE, R. G. 2002 clinical practice guidelines for the diagnosis and management of osteoporosis in Canada. Can Med Assoc J, v. 167, n. I0, p. sl-s34, 2002.

9. BURR, D. B. et al. Bone microdamage and skeletal fragility in osteoporotic and stress fractures. B Bone Miner Res, v. I2, n. I, p. 557-62, 1997.

10.CANALIS, E.The hormonal and local regulation of bone formation. Endocr Rev, v. 4, n. I, p. 62-77, 1983.

I।. CESNJAJ, M.; STAVLJENIC, A.; VUKICEVIC, S. Decrease osteoinductive potential of bone matrix from ovariectomized rats. Acta Orthop Scand, v. 62, n. 5, p. 47I-5, 199 I.

12. COMPSTON, J. E. Sex steroids and bone. Physiological Reviews, v. 8I, n. I, p. 419-47, 2001 .

13. CONSENSUS Development Conference: diagnostic, prophylaxis, and treatment of osteoporosis. Am J Med, v. 94, p. 646-50, 1993 (conference report).

14. DALLAS, S. L. et al. Characterization and autoregulation of latent transforming growth factor beta (TGF-beta) complexes en osteoblast-like cell lines: production of a latent complex lacking the latent TGF-beta-binding protein. J Biol Chem, v. 269, n. 4, p. 6815-22, 1994.
15. DI RENZO, G. C. et al. Management of postmenopausal osteoporosis.J Obstet Gynecol, v. 56, p. 47-53, 1994.

16. DUONG, L. T.; RODAN, G. A. Regulation of osteoclast formation and function. Rev Endocr Metab Disord, v. 2, p. 95-104, 2001.

17. ERIKSEN, E. F. et al. Evidence of estrogen receptors in normal human osteoblas-like cells. Science, v. 24I, p. 84-6, 1988.

I8. FROST,H. M.A new direction for osteoporosis research: a review and proposal. Bone, v. I2, p. 429-37, I991.

19. FULLER, K.; GALLAGHER, A. C.; CHAMBERS, T. J. Osteoclast resorption: stimulating activity is associated with the osteoblast cell surface and/or the extracellular matrix. Biochem Biophis Res Commun, v. 181, n. I, p. 67-73, 1991.

20. GENANT, H. K et al. Interium Report and Recommendations of the World Health Organization Task-Force for Osteoporosis. Osteoporosos Int, v. 10, p. 259-264, 1999

21. GRAY, T. K. Estrogens and skeleton: cellular and molecular mechanisms. J Steroid Biochem, v. 34, n. I-6, p. 285-7, 1989.

22. HANABAYASHI,T.; IMAI, A.; TAMAYA, T. Effects of ipriflavone and estriol on postmenopausal osteoporotic chances. Int Ginecol Obstet, v. 5I, p. 63-4, 1995.

23. HILL, P. A.; ORTH, M. Bone remodeling. Br J Orthod, v. 25, n. 2, p. IOI-7, 1998.

24. HOLLINGER,J.;WONG, M. E. K.The integrated processes of hard tissue regeneration with especial emphasis on fracture healing. Oral Surg Oral Med Oral Pathol, v. 82, n. 6, p. 594-606, 1996.

25. HOROWITZ, M. C. Citokines and estrogen in bone. Science, v. 260, n. 5108, p. 626-7, 1993.

26. HSIEH,Y. D.; DEVLIN, H.; MCCORD, F.The effect of ovariectomy on the healing tooth socket of the rat. Arch Oral Biol, v. 40, n. 6, p. 529-31, 1995.

27. HUGHES, D. E. et al. Estrogen promotes apoptosis of murine osteoclasts mediated by TGF-beta. Nat Med, v. 2, n. 10, p. I132-6, 1996.

28.JUNQUEIRA, J.C. et al. Effects of sinvastatin on bone regeneration in the mandibles of ovariectomized rats on blood cholesterol level.J Oral Sci, v. 44, n. 3/4, p. I 17-24, 2002. 
29. JUNQUEIRA, L. C.; CARNEIRO, J. Tecido ósseo. In: Histologia básica. 9 ed. Rio de Janeiro: Guanabara-Koogan, 1999. cap. 8, p. III-28.

30. KATCHBURIAN, E.; ARANA, V. Tecido ósseo. In: Histologia e embriologia oral. São Paulo: Panamericana, 1999. cap.3, p. 40-75.

31.KAWAMOTO, S.; NAGAOKA, E.The effect of estrogen deficiency on the alveolar bone resorption caused by traumatic occlusion. J Oral Rehabil, v. 27, n. 7, p. 587-94, 2000.

32. KESSEL, R. G.Tecido conjuntivo: osso e formação óssea. In: Histologia médica básica: a biologia das células, tecidos e órgãos. Trad. M.c. Engelhardt. Rio de Janeiro: Guanabara Koogan, 200 I. cap. 7, p. $129-45$.

33. KOBAYASHI, T.; KRONENBERG, $H$. Minireview: transcriptional regulation indevelopment bone. Endocrinology, v. I46, n. 3, p. 1012-7, 2005.

34. KOMM, B. S. et al. Estrogen binding, receptor $m R N A$, and biologic response in osteoblast-like osteosarcoma cells. Science, v. 24I, n. 468I, p. 8I-3, 1988 .

35. KUBO,T.et al. Osteoporosis influences the late period of fracture healing in a rat model prepared by ovariectomy and low calcium diet. I Steroid Biochem Mol Biol, v. 68, n. 5-6, p. $197-$ 202, 1999.

36. LILL, C.A. et al. Biomechanical evaluation of healing in a non-critical defect in a large animal model of osteoporosis.J Orthopaedic Res, v. 21, p. 836-42, 2003

37. MANOLAGAS, S. C. Role of cytokines in bone resorption. Bone, v. 17, n. 2, suppl., p. 63-7, 1995.

38. MANOLAGAS, S. C.; IILKA, R. L. Mechanisms of diseases: bone marrow, citokynes, and bone remodeling: emerging insights into the pathophysiology of osteoporosis. N Engl J Med, v. 332, n. 5, p. 305-I I, 1995.

39. MARIE, P.J. et al. Osteocalcin and deoxyribonucleic acid synthesis in vitro and histomorphometric indices of bone formation in postmenopausal osteoporosis. J Clin Endocrinol Metab, v. 69, n. 2, p. 272-9, 1989.

40. McKEE, M. D. et al. Ultrastructural immunolocalization of noncollagenous (osteopontin and osteocalcin) and plasma (albumin and alfa-2-HS-glycoprotein) proteins in rat bone. Bone Miner Res, v. 8, n. 4, p. 485-96, 1993.

4I. MEGHII, S. Bone remodeling. Br Dent J, v. I72, n. 6, p. 235-42 1992

42. MEIKLE, M. C. et al. Human osteoblasts in culture synthesize collagenase and other matrix metalloproteinases in response to osteotropic hormones and cytokines. J Cell Sci, v. I03, p. 1093-9, 1992.

43. MODESTO FILHO, .:; AZEVEDO, L. A. P.; AZEVEDO, L. C. P. Tratamento da osteoporose.J Bras Med, v. 7I, n. 5/6, p. 77-9, 1996.

44. MOREIRA, C. Osteoporose. In: ROCHA, M. O. C. et al. Terapêutica clínica. Rio de Janeiro: Guanabara Koogan, 1998. cap.67, p. 588-604

45. MOURAD, L. A. Structure and function of the musculoskeletal system. In: McCANCE, K. L.; HUETHER, S. E. Pathophysiology: the biologic basis for disease in adults and children. 3. ed. Sant Louis: Mosby, 1997. cap. 4I, p. 1405-85.

46. MUNDY, G. R. Cellular and molecular regulation of bone turnover. Bone, v. 24, n. 5, suppl., p. 35-8, 1999.

47. MUNDY, G.R. et al.The effects of cytokines and growth factors on osteoblastic cells. Bone, v. 7, n. 2, suppl., p. 7| s-5s, 1995.

48.NAJJAR,T:; KAHN, D. Comparative study of healing and remodeling in various bones. J Oral Surg, v. 35, n. 5, p. 375-9, 1977.

49. NAMKUNG-MATTAI, H. et al. Osteoporosis influences the early period of fracture in a rat osteoporotic model. Bone, v. 28, p. $80-6,2001$

50. ROODMAN, G. D. Advances in bone biology: the osteoclast. Endocr Rev, v. I7, n. 4, p. 308-32, 1996.

5I. RORIES, C.; SPELSBERG, T. C. Ovarian steroid action on gene expression: mechanisms and models. Annu Rev Physiol, v. 5 I p. 653-8I, 1989.

52. SCHENK, R. K. Bone regeneration: biologic basis. In: BUSER. D.; DAHLIN, C.; SCHENK, R. K. Guided bone regeneration in implant dendistry. Chicago: Quintenssense Books, 1994. cap. 3, p. 49- 100.

53. SHIMIZU, M. et al. bone wound healing after maxillary molar extraction in ovariectomized aged rats. Journal of Electron Microscopy, v. 47, n. 5, p. 517-26, 1998.

54. STEEVE, K. T. et al. IL-6, RANKL, TNF-alpha/IL- I: interrelations in bone resorption pathophysiology. Citokine Growth Factor Rev, v. 15, p. 49-60, 2004.

55. SUDA, T. et al. Regulation of osteoclast function.J Bone Miner Res, v. 12, n. 6, p. 869-79, 1997.

56. SUDA, T. et al. Modulation of osteoclast differentiation by local factors. Bone, v. 17, suppl. n. 2, p. 87s-9 Is, 1995

57. SZACHOWICZ, E. H. Facial bone wound healing. Otolaringol Clin North Am, v. 28, n. 5, p. 865-8I, 1995.

58. SZEJNFELD,V. L. Osteoporose: diagnóstico e tratamento. São Paulo: Sarvier, 2000. 406p.

59. TANAKA, M. et al. The effect of aging and ovariectomy on mandibular condyle in rats. J Prosthet Dent, v. 79, n. 6, p. 68590, 1998.

60.TROWBRIDGE, H. O; EMLING, R. C. Regeneração e cicatrização. In: Inflamação: uma revisão do processo. 4 ed. São Paulo: Quintessence, 1996. cap. 7. p. 146-7.

61. TURNER, C. H.; ROBLING, A. Mechanical loading and bone formation. Bonekey-Osteovision, v. I, n. 9, p. I5-23, 2004.

62. TURNER, R. T.; RIGGS, B. L: SPELSBERG, T. C. Skeletal effects of estrogen. Endocrine Rev, v. 15, n. 3, p. 275-300, 1994.

63.WALSH,W. R. et al. Fracture healing in rat osteopenia model. Clin Orthop, v. 342, p. 218-27, 1997

64.WILLIAMS, C. L;;STANGEL,G. M. Estrógenos e progestogênios. In: GOODMAN. GILMAN. As bases farmacológicas da terapêutica. 9. ed. Rio de Janeiro: Mc Graw Hill, 1996. cap. 57, p. I045-67.

65. XU, S.W. et al. Early period of fracture healing in ovariectomized rats. Chin J Traumatol, v. 6, n. 3, p. 160-6, 2003 